sufferer was subjected during the four days which elapsed from the time of the accident to the period of his demise; and the last, by the peculiar nature of the injury and the form of the wound, which, by retaining the water within the bladder, would seem to have occasioned the proper action of that viscus. That some water escaped, I am not, however, prepared to deny, notwithstanding that the little which was discovered in the cavity of the abdomen did not emit an urinous odour. The most wonderful circumstance in connection with the case appears to be the length of time during which the pa. tient lived under so severe an infliction.

Elland, near Halifax, April 4, 1842.

\section{TREATMENT OF VARICOSE VEINS} WITH THE VIENNA PASTE.

\section{To the Editor of THe LAxCET.}

SIR,-In July, 1810, I had the pleasure of forwarding to you a description of a new operation, or rather of a modification of an old operation, introduced by MI. Laugier, surgeon to the Hopital Beaujon, of Paris, for the cure of varicose veins. The publication in the "Gazette Médicale de Paris," Jan. 22, 1842, of an article by M. Berard, on the cure of varices by the Vienna paste, affords me an opportunity of making a few additional remarks on this subject, which, though of but little importance in the opinion of many surgeons, still merits serious attention from all, from the frequency of the disease and the great distress attendant on it.

The cure of varices by cauterisation with the caustic potass was first attempted by Ambrose Pare, and his method has been followed, with different dezrees of success, by various surgeons, up to the present time. liecommended by some, it has been objected to by others as dangerous, and by Sir $\mathbf{B}$. Brodie as affording but an inadequate compensation for the pain to which the patient is subjected by the use of the caustic, and the inconvenience resulting from the tedious healing of the alcer which remains after the separation of the slough. In Niay and June, 1839; M. Bonnet, of Lyons, published in the "Archives Générales de Méd.," an article in farour of the caustic potass, and gave the details of several operations in which its application had been successful. But the principal objections to its use, as recommended by Paré, Sir $\mathbf{B}$. Brodie, M. Bonnet, and others, still existed. Its application, so as to make a slough of the skin and vein beneath it, was often followed by severe inflammation of the cauterised vein, resulting in most cases from inelficient cauterisation; and the extent of the ulcer, after the separation of the slough, was still No, 976 . a serious objection to its general application.

To obviate these, M. Laugier was induced to modify Parés method of operating, and, before applying the caustic, to follow the directious given by Celsus, in his chapter "de varicibus :"-"Cutis superinciditur : tum patefacta vena, tenui et retuso fesramento candente modice premitur," - substituting for the actual cautery recommended by Celsus, and fur the caustic potass, a preparation known under the name of Vienna paste.

It is unnecessary for me to recapitulate all the advantages belonging to $M$. Laugier's plan of dividing the skin before applying the paste on the dilated vein. I would simply refer your reader's to my article of $\mathbf{J}$ uly $\mathbf{1 8}$, 1810 , and to the subsequent communications from $\mathrm{Mr}$, Clay, of MIanchester. (See LANCET, July 18, Aug. 29, Oct. 17, Dec. 12, 1840, and July 24, 1841.)

Of forty-four patients who entered the Hopital Beaujon, between the months of May, 1839, and June, 1840, to be operated on by $\mathrm{MI}$. Laugier for varices, twenty-five were men, nineteen women. Of the latter thirteen were washerwomen, who passed from nine to ten hours a-day standing; of the twenty-five men, all, with the exception of two, were daily employed in laborious occupations, requiring either prolonged station, or constant violent exercise of the inferior extremities.

The longest duralion of treatment was one hundred and seventy-four days, the shortest thirteen. The average time passed in hospital was about fifty-six days.

Mr. Clay would seem, however, to have been more successful. In the cases operated on by him the slough fell, on an average, about the fourteenth day from the operation, the wounds healing rapidly afterwards. In his letter of July, 1841, he says, speaking of females, "In young and healthy habits the sores will be quite healed in three weeks, but in those of advanced age, debilitated constitutions, and stinted means of subsistence, it will take from four to five weeks." Perhaps the difference in the time required for complete recovery between these gentlemen's cases, may depend on Mr. Clay's having dismissed his patients immediately after the healing of the wounds, whilst $M$. Langier kept his patients in the hospital for several days after cure, wishing to ascertain whether the relief obtained was permanent, or whether exercise would cause a reappearance of the varices. And here I may add, that $I$ have seen most of the forty-four cases several months, some of them eighteen months, after the operation, and in all, with very few exceptions, the cure was perfect. Respecting these exceptions, in one or two the neighbouring veins had become slightly varicose; in others, there was a tendency in the originally dilated reins to reassume their 
primitive varicose state above and below the obliterated spots.

In my first communication I expressed my belief, founded on the observation of from forty to fifty cases, that the operation, if properly performed, and with the necessary precautions, was almost without danger; and, although $I$ have since seen one case of death resulting from it, further observation has only strengthened my first opinion. regret that accident has occasioned the loss of the notes I had taken of this fatal case, but the following are the principal features of it, which I quote from memory. The unfortunate patient was a man of vigorous constitution, having a large ulcer on the inner side of the leg, depending on a varicose state of the neighbouring veins, principally the internal saphena. M. Laugier operated on the internal saphena above and below the knee; everything went on favourably for fifteen days; the dilated veins diminished; the ulcer healed rapidly, but there was some tenderness on the separation of the sloughs. Restless of confinement, the patient, although strictly forbidden, rose from his bed several times; diffused phlebitis supervened, and notwithstanding the most vigorous treatment, terminated fatally in a few days.

It cannot be denied that death in this case resulted from the operation; but it is probable that a different result might have been obtained, if, like all the other patients operated on by M. Laugier, he had followed the directions so strictly enjoined, to remain quiet until the sloughs had separated.

"I am now," says Mr. Clay, "so perfectly convinced of the benefit of this operation, that I consider it invaluable; but it is an operation that requires not only great care in the performance, but considerable atten. tion to the threatening symptoms of inflammatory action afterwards." In this I perfectly agree with him. By proper attention to the performance of the operation, and to the subsequent treatment, watching with care the slightest appearance of infammation, and, above all, by strictly keeping the patient in bed till the sloughs have fallen, I have no hesitation in saying that the occurrence of phlebitis will be extremely rare, and that if it should appear, it will be more of a circumscribed than of a diffuse nature.

But to return to M. Berard's article, which, as I said before, was the principal cause of $\mathrm{my}$ thus troubling you. $\mathrm{M}$. Berard, surgeon to the Hopital Necker, advocates the method originally employed, but subsequently discarded by M. Laugier, of applying the Vienna paste on the skin, over the vein, following Pare's method of operating, simply substituting the paste for the caustic potass. But what is more surprising, he seems to claim for himself the merit of having been the first to apply this caustic to the cure of varicose veins, having wholly forgotten, or willingly overlooked, the various publications of M. Laugier on this subject, contained in his " Bulletin Chirurgical," 1839.

There is one point, however, on which M, Berard can with greater justice found his claim to originality. Instead of applying the paste so as to make a circular slough of the skin and vein, he places a single layer of it, from one to two inches in length, and from three to five lines in breadth; thus producing a long narrow eschar, the advantages of which, according to him, are great, for the following reasons :- First, that by thus operating he obtains a greater disorganisation of the vein than by the circular slough. Secondly, that the wound, after the separation of the slough, being long and narrow, heals more rapidly than if it were circular. And, thirdly, that the cicatrix, somewhat similar to that of an incised wound, is less evident and less liable to ulceration.

The two last reasons may, perhaps, be good, but I know not whether our obtaining such an extensive obliteration of the vein, as would result from the application of a layer of caustic from an inch to two inches in length, is desirable. Our object in operating should not be so much to produce total obliteration of the dilated vein as a partial occlusion of it. The application of a small portion of the paste, according to MI. Laugier's method, is sufficient, in nearly every instance, to relieve the most severe case of varix, not only by rendering a certain portion of the vein, above and below the cauterised spot, impervious, but also, as it would seem, by restoring to the dilated vein some of its former tonicity, causing it to contract, and rendering it capable of resisting the dilating action of the blood. Besides, the separation of a slough, such as would result from M. Berard's operation, must be extremely tedious.

But it is a matter of very little importance whether we produce a circular, transverse, oblique, or perpendicular slongh; our object is to obliterate a certain portion of the dilated vein, and to obtain this we should follow the most efficacious and innocent method. It is because it possesses these qualities, that $\mathbf{M}$. Laugier's operation is so valuable. His substituting the Vienna paste to the other caustics is of minor importance, compared with his having reintroduced the ancient method of exposing the vein before applying the caustic. By proceeding thos, he produces a speedy and certain destructiol of the vein; whilst, by applying the caustic on the skin undivided, it frequently happens, as M. Berard himself admits, that the veill is unaffected, or but partially affected by it. Hence, $I$ apprehend, the frequency of phle. bitis as a consequence of Parés method of operating.

There are several other points on which I would wish to make a few remarks, but as 
I bave already lengthened my letter far beyoud my original intention, $I$ must content myself with briefly noticing the following most objectionable lines in M. Berard's article.

"After keeping the patients quiet for three or four days after the operation," says M. Berard, "we may allow them, if the eschar be dry, and no swelling exist in the course of the vein, to return to their ordimary occupations, however laborious they may be."

Comment on the above lines would be useless. The folly and temerity of thus allowing the patients not only to rise from their beds, but even to return to " their occupations, however laborious they may be," before the sloughs have separated, cannot be too severely reprobated; and if experience has not already shown M. Berard the danger of his practice, I trust that he may not have one of these days to regret not having followed the ordinary precepts of prudence. I remain, Sir, your obedient servant,

53, Clarendon-street.

E. Scratchley，M.D.

\section{ON THE}

\section{PRINCIPLES OF TREATMENT}

$\mathrm{OF}$

PULMONARY CONSUMPTION. By W. Wilson, M.D.,

Physician to the West London Institution for Diseases of the Chest.

In allusion to a preceding paper on Tubercular Consumption, inserted in THE LANCET of February last, $\boldsymbol{I}$ wish to lay before my professional brethren a more enlarged view of the principles $I$ advocate and the treatment $I$ adopt in cases of phthisis. I am fully aware of the extreme difficulty that presents itself, to combat with the old and confirmed prejudices entertained by the majority of my profession and the public against the curability of consumption, and I must admit that medical records but serve to strengthen such conclusions; but an enlightened and liberal profession should be open to conviction, free to embrace facts, and earnest to solicit inquiry. We well know to what a surprising extent prejudice has blinded us to the most valuable remedies. Secale cornutum, one of the most valuable remedial agents we possess, was a popular remedy hefore the medical world would admit it into their vocabulary. Iodine, to a great extent, shared the same fate; and the physician who had the hardihood to recommend the internal administration of cantharides was prosecuted, and suffered the penalty of his sagacity, but taught his followers the safety and value of his practice. Doubtless a new system of treatment and new remedies should be received with due caution, but divested of all prejudice. If certain results and certain facts are stated, a fair trial of their intrinsic worth should be made, and particularly if they refer to a disease which to a melancholy extent has baffled medical skill, and defied the ingenuity of the greatest talent. I know full well that there are to be found medical men, eminent in station and talent, who, to illustrate their views, in conformity with preconceived prejudices, would present a wretched case of phthisis in which disease had made frightful progress, and in which the symptoms were strongly indicative of approaching dissolution, and ask if it were possible a cure could be effected in such a case? I should say certainly not, no more than a cure could be expected in a parallel case of peritonitis, hepatitis, fever, or in any other disease the treatment of which is well understood.

I saw a lecturer of eminence exhibit to his class a diseased lung, the structure of which was nearly destroyed by ulceration : "And am I to be told," he gravely asked, " that a visit to the South of France could have cured this patient?" He evidently had a great objection, at certain stages of phthisis, to the patient going to a warmer climate than our own.

I am well aware that many cases of tubercular consumption present such unequivocal appearances of extensive disease, that no treatment, however judicions, can be of much avail, such as acute cases, one in which there is extensive tubercular development, and in which the softening process has commenced almost simultaneously in both lungs, this is generally fatal ; for if a chance were left, time is wanting to test the virtues of any mode of treatment. But to place this very fatal disease under better control, the treatment must be fixed on a more permanent basis than the vacillating and uncertain practice hitherto adopted, with the object of relief or cure; and the treatment I have pursued in this disease convinces me, by its singular success, that all hope of a cure in this prevalent and fatal complaint is not so groundless as has been hitherto imagined. I fear no inquiries by the confident recommendation of the treatment $I$ adopt in phthisis, but should feel most happy to give my professional brethren an opportunity of judging for themselves.

From great observation I am of opinion that there is an intimate relation between scrofula and consumption, and that the same causes would produce one as the other, regulated by this difference, that scrofula is more a disease of infancy than phthisis. A medical gentleman assured me that in a foundling hospital much overcrowded with young children, the majority of them reared in the country, were on admission strong and 